\title{
Pre-service teachers on action research: Towards a training model for the task
}

Montebon, Darryl Roy T.

Philippine Normal University, Philippines (montebon.drt@pnu.edu.ph)

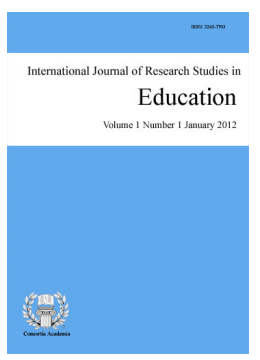

Accepted: 2 August 2021 Online ISSN: 2243-7711

OPEN ACCESS

\section{Abstract}

This study is to pre-service teachers' readiness on action research and to inform new practices in preparing them for the task. Specifically, the study investigates pre-service teachers' conceptual understanding, perception, and readiness for action research. A Plan Do Study Act (PDSA) model guided the conduct of the study participated by 38 pre-service science teachers. The researcher-designed questionnaire and the analysis of the different action research outputs submitted show that the pre-service teachers possess varied conceptual understandings of the characteristic of action research, and it seemed to have guided them in the conduct of the task. Further, the results from the questionnaire seemed to show that the pre-service teachers realized the different benefits of doing action research upon exposure to the task. Though the pre-service teachers reported that they are in general 'ready' for the different action research tasks, the quality of their outputs still needs improvement. Thus, further support for action research is needed. Ultimately, the study results in a model for preparing-plan, practice, process, present, and promulgate.

Keywords: action research, pre-service teachers, Philippines, practice teaching experience; $4 \mathrm{P}$ model, conceptual understanding, challenges 


\section{Pre-service teachers on action research: Towards a training model for the task}

\section{Introduction}

Teachers in the classroom encounter teaching and learning situations that can challenge their decision-making skills. To make sound judgment, teachers employ scientific procedures like identifying the problem, creating a hypothesis, and testing ideas. As teachers solve the problems confronting them in the classroom, they are already doing a form of research (Ulla et al., 2017). Thus, in a certain sense, teaching and research are inseparable; though they may be viewed to be two independent entities, in education, they are complimentary of each other--for research makes teachers 'reflective practitioners'. Researchers agree that by undergoing the processes of research, teachers can assess what methods work best in their classrooms and what do not; thus, a reflection of practice happens (Rademaker, 2013; Morales, 2016). In effect, the end product of teachers' constant reflection is improved practice.

Nevertheless, mere thinking of the term 'research' can make a teacher reluctant about it; for, 'research' in general is broad. Therefore, teachers should be able to choose which will help them best--in this study, it is identified as action research. Why action research? Morales (2016) argues that teachers as agents of change should indulge in action research for it is evidence that professional development is practiced. Simply put, teachers as professionals can act through research to continuously improve their practice. In the same vein, Soprano and Yang (2012) suggested that action research is best for teachers for the said practice entail a constant cycle of reflection, assessment, and action. In other words, as practitioners, teachers are always exposed to problems that call for contextual solutions that action research can accurately provide. Ulla et al. (2017) agree that action research is best suited for teachers because of the nature of its context that can be constructed personally and socially in the domains of teaching and learning.

Action research as a relevant practice in teacher development is also encouraged in the basic education schools of the country. Manguerra (2019) in a seminar-workshop described that the Department of Education in the Philippines is giving a primer on action research for its potential to provide contextual solutions to the challenges faced by teachers in the classroom and even in the school system. Acknowledging the importance of action research in the teaching profession, the present research posits that pre-service teachers should be trained for the challenge. It is advocated in the research locale being a prime institution that provides the Country with a significant number of teachers be responsive to their needs in terms of content and skills for doing action research. Hence, conducting action research is an experience provided for pre-service teachers in their practice teaching experiences.

With the research locale's institutional practice of encouraging the conduct of action research (AR) as part of the practice teaching experience, the researcher is interested to find how pre-service teachers' underlying ideas and perception of AR influence them to do the task. More importantly, the researcher aims to determine the level of readiness of pre-service teachers for conducting AR.

Specifically, the following are the research questions answered in this study:

$>$ What are the conceptual understandings of the pre-service teachers on action research?

$>\quad$ How do pre-service teachers perceive the task of action research?

$>\quad$ How ready are the pre-service teachers to do action research?

$>\quad$ What training model can be developed from the process of exposing pre-service teachers to action research tasks? 


\subsection{Action Research and its forms}

The definition of action research is complex. According to Dick (2015), action research is a continuous process of reflection, investigation, and taking action. Further, Dick (2015) describes that action research always has a twin goal of understanding and theory; however, "action" should always be primary. In effect, action research binds the action and reflection process, bridges theory and practice, and results in practical solutions to the problem. Such outcomes are all essential for developing pre-service teachers. Thus, the researcher posits that it should be included in the professional training of pre-service teachers.

Action research as an educational endeavor can be done for certain purposes but generally, researchers identify that the practice is an impetus for reflective practice (Rademaker, 2013; Morales, 2016; Soprano \& Yang 2012; Ryan et al., 2017). It means that through action research, teachers follow a cyclical process to constantly reflect on their practices and take actions to improve in their professions. Dick (2015) described that action research as a form of reflective practice encourages teachers to be critical because they can gain and discover new knowledge. The process itself enhances students' concept of the ideas they are investigating. Action research can also be a form of an appreciative inquiry that helps to identify the strength of a certain organization or committee and builds on them. Through the reflective nature of action research, students can assess the strengths and weaknesses of certain practices and even their prejudices on the concepts they are studying about. Through action research, students can see ideas in a different light and transform their worldviews into the appreciation of the ideas they discover. Additionally, action research can also be employed in the analysis of system-based information in problem-solving situations by letting pre-service teachers identify different challenges in the classroom and assess how they can be addressed. In practical terms, action research can be a 'soft' approach to 'hard' problems, thus it is a form of soft-system methodology. Lastly, the conduct of action research involves the strong cooperation of several stakeholders because its nature is participatory. Action research as an enterprise requires collaboration among different stakeholders. In the case of this research, action research is a task that involves the pre-service teachers, the university supervisors, and the respondents of the specific studies.

\subsection{Action Research for Pre-service Teachers}

Action research as a model of professional development practice has been recognized by researchers to affect pre-service teachers (Hobson et al., 2015; Kennedy-Clark et al., 2018; Soprano \& Yang, 2013; Ryan et al., 2017; Clayton \& Meadows, 2013; Ulvik \& Reise, 2016). Primarily, Hobson et al. (2015) describe that through action research, pre-service teachers can connect practices that are research-based in their teaching, utilize information to reflect on their practices, apply personal information gained to make professional decisions, present finding to peers for professional critiquing and foster lifelong learning in their teaching and academic studies. Simply put, by doing action research, pre-service teachers can apply the knowledge that they gained in new classroom situations and problems. Upon the realization of the importance of training pre-service teachers for action research, researchers suggest its integration in the practice teaching praxis (Lattimer, 2012; Ryan et al., 2017; Kennedy-Clark et.al., 2018.).

However, Kennedy-Clark et.al (2018) argue that there is no question on the benefits of exposing pre-service teachers to the challenges of action research, but more importantly, its placement in the teacher education program needs careful study. In response, Ryan et.al. (2017) suggest that the conduct of action research should be placed on the practicum stage of teacher preparation for the said phase is a trial and error stage. During the practicum, pre-service teachers can afford to try out different ideas that they think would best work in their classrooms. Consequently, pre-service teachers can gain significant insights into how teaching and learning works.

But why do pre-service teachers find it hard to make action research? Is it because they don't know how to do it, or they simply do not understand its nature? The challenge of doing action research for our undergraduate students is primarily anchored on their confidence to do the task (Hobson et al., 2015). Lattimer (2012) described 
the pre-service teachers as novice practitioners who are expected to face challenges as they venture into the conduct of action research. The idea of doing research and undergoing its rigorous task shuts off students' interest to proceed. Such difficulty may have been due to their self-assessment of their research skills. Hence, mentoring students on how to proceed with the process of the study is a necessity. Hobson et al. (2015) suggest that mentoring undergraduate students on how to do action research can lead to a greater sense of belongingness and establish connectedness between the students and the school that may result in persistence through graduation.

Though there are challenges to be encountered in promoting action research to pre-service teachers, it should be strongly encouraged. Lattimer (2012) said that for sure costs and obstacles are integral to the process of training pre-service teachers for action research. Nevertheless, it should be done because at the end of the process benefits can outweigh the costs and that the pre-service teachers who experienced action research have more quality and value-added to become an effective teacher someday.

\subsection{Conceptual Framework}

The ideas from the different studies reviewed on action research and its integration in the practice teaching activities guided the researcher to create the conceptual framework of the study shown in Figure 1.

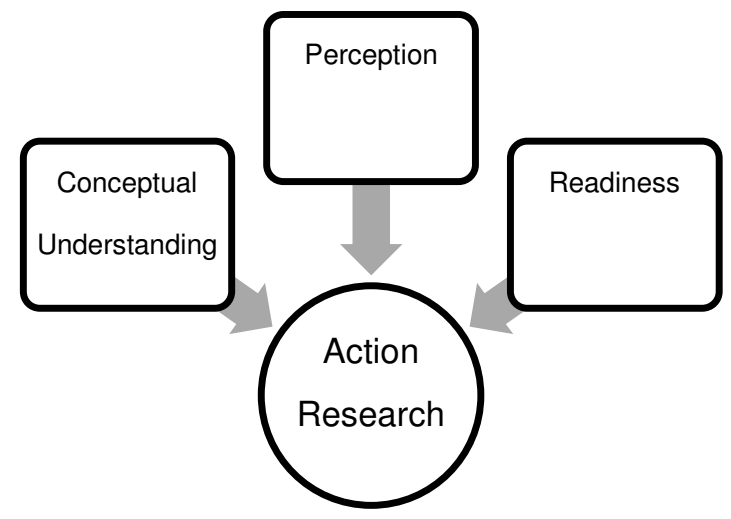

Figure 1. Conceptual Framework

Figure 1 shows the three constructs that seemed to affect pre-service teachers' ability to perform the task-conceptual understanding, perception, and readiness. First, conceptual understanding or the ability to comprehend micro or macro concepts is essential for ideas lead to action. In other words, a person with sound conceptual understanding realizes the meaning of a construct in its truest sense and therefore exhibits appropriate behavior when confronted with situations that require cognitive decisions (Wees, 2018). In the present research, the need to identify pre-service teachers' conceptual understanding of action research due to their exposure to the task is deemed important for the researcher posits that sound conceptual understanding results in desirable behaviors and eventually effective teaching practices. As Hobson et al. (2015) stressed, the pre-service teachers' understanding of the nature of the action research and its processes can affect their self-efficacy on the task. Simply put, pre-service teachers' correct understanding of the nature and characteristics of action research are believed to affect their readiness and willingness to perform the task. Therefore, it is the aim of the present study to identify pre-service teachers' conceptual understanding of action research and how it affects their performance for the task.

Second, the different literature reviewed identified the benefits of the action research as a form of a formalized reflective practice and a model of professional development. However, the ideas in the studies reviewed were the observations of the researchers and not reports of pre-service teachers themselves on their experiences while conducting the study. Thus, another aim of the study is to address the gap in the knowledge of how pre-service teachers perceive the task and its importance in developing them to become effective teachers in

22 Consortia Academia Publishing (A partner of Network of Professional Researchers and Educators) 
the future.

Lastly, the researcher investigated the level of readiness of the pre-service to perform the task. The literature suggests that among the three constructs identified, pre-service teachers' readiness to do AR is the most important. Similarly, the researcher conducted this study to determine specific areas that the designed program to assist pre-service teachers can be more contextual and responsive.

\section{Methodology}

\subsection{Setting and Respondents of the Study}

This research has been conducted at a Teacher Education Institute in the Philippines where the respondents were in their final year and had their practice teaching program. The researcher purposely identified the thirty-eight $(\mathrm{N}=38)$ science pre-service teachers set to have their practice teaching in public schools for the identified period. Specifically, there were twenty-three (23) pre-service teachers with specialization in Biology and fifteen (15) pre-service teachers taking Chemistry.

\subsection{Instrument and Data Sources}

To investigate pre-service teachers' ideas on the action research tasks, the researcher prepared a questionnaire that includes several questions and a checklist on their level of readiness for the task. The researcher-made questionnaire was validated by his colleagues at the Institute who are also supervising the pre-service teachers in the practice teaching program. The questionnaire was administered after the pre-service teachers conduct action research.

Another important data source that was considered by the researcher is the actual action research (AR) outputs submitted by the pre-service teachers. Since the task for doing the action research is by group, there were about ten (10) action researches that were submitted to the researcher. The ten AR outputs were analyzed using the existing rubric of the Institute for grading the outputs of the pre-service teachers.

\subsection{Data Collection and Analysis}

To answer the questions raised in the present research, the PDSA (4-step) model was used. According to Zogbhi (2012, p. 76), the PDSA model is a "4-step model for continuously improving [educational] processes and products". How the PDSA model was used in the study is discussed in this section of the paper.

Planning for action - In preparation for the conduct of the study, the researcher presented his initial plans to his other colleagues and the Director of the Institute about his plans of studying how the integration of action research in the practice teaching practices affect pre-service teachers. The plans of the researcher were included in the finalization of the orientation period for pre-service teachers.

Doing the Action - In the 'do' stage, the researcher conducted a lecture-workshop on action research among the respondents identified. First, the researcher conducted a lecture on action research among pre-service teacher respondents. The respondents were given time to ask questions and clarify ideas on action research. After the lecture, the workshop followed suit. In the workshop, the pre-service teachers were grouped according to their school assignment for their off-campus practice teaching. Each group was assigned to brainstorm on what problems in the classroom they would like to investigate and they made an action research proposal about it. However, the finalization of the topic for action research happened in the practice teaching site. Some modifications were noted on the proposed topic based on the suggestions of the critic teachers of the pre-service teachers. Upon approval by their respective school principal or critic teachers, the pre-service teachers then conducted their action researches. The researcher as the university supervisor of the pre-service teachers continuously monitored the pre-service teachers in the conduct of their study and advised some methods how to 
better address the problem being solved.

Studying the effects - The data gathered through the given questionnaire were analyzed as to the nature of the information. Since the questionnaire included both qualitative and quantitative data, the researcher used the multi-method research design to interpret the results appropriately. For the first two questions of the questionnaire, qualitative research methods were employed to analyze the answers of respondents on the questionnaire. The answers that were gathered were coded and were classified according to the dominant themes occurring. To support pre-service teachers' concept of action research, their AR outputs were analyzed and were cited as examples. On the other hand, the quantitative methods of data analysis were used in analyzing the answers of the pre-service teachers. The results of the questionnaire were interpreted using descriptive analysis procedures specifically - the mean. Such is to determine pre-service teachers' level of readiness for the task. To support pre-service teachers' claims on their readiness for the AR tasks, the researcher juxtaposed the data with the assessment reports of their actual outputs. The juxtaposed data were analyzed to find points of coherence and determine areas for improvement. To establish the validity and reliability of the data collected, the researcher discussed with the participants the result of the study to determine if the analysis of the researcher represent their ideas and experiences.

Reflecting for further Action - With the results of the present research, the researcher reflected on the specific practices that he had observed being conducted in promoting the conduct of AR among pre-service teachers. Consequently, the researcher presents specific steps in assisting pre-service teachers in doing action research. The said steps are discussed in the last part of the paper.

\subsection{Ethical Standards}

The researcher gathered informed consent among the participants through the researcher questionnaire that was distributed. Through the questionnaire, the researcher informed the participants that their involvement in the study is voluntary and that they can withdraw anytime should they feel uncomfortable with the process. Also, the researchers informed the participants that they will not receive any monetary or other forms of incentives as they participate in the study. The researcher assured the pre-service teachers that their responses will not in any way affect their class standing or grades for their practicum course.

\section{Results and Discussion}

\subsection{Conceptual understanding of pre-service teachers on action research}

Table 1 shows the summary of responses on the pre-service teachers' concept of the characteristic of action research from the survey questionnaire conducted. Moreover, the responses are classified according to the characteristics of action research identified by Dick (2015).

Based on Table 1, it may be inferred that the respondents acknowledged the critical nature of action research. With the critical nature of action research, the researcher means that pre-service teachers seemed to understand that action research can be used to reflect on how theories are utilized in promoting better understanding among students. The conceptual understanding of the respondents on the critical nature of action research is similar to other researchers who described that the study is to challenge the existing theories and practices in the teaching and learning processes to promote better and correct understanding (Dick, 2015). As Respondent 1 said, "[a]ction research is used to identify and to solve particular problems (i.e. subject areas, curriculum, students' behavior, classroom management, and pedagogy) in education.”

The conceptual understanding of the respondents on the critical nature of action research seemed to direct them to explore ways to improve the quality of their teaching by providing solutions to the problems that they may encounter in the classroom. The respondents' idea on the critical nature of action research is evidenced by 
Pre-service teachers on action research: Towards a training model for the task

their output on the task. Among the AR outputs collected, two outputs explored how behaviorism works in the classroom and how it affects students. The output of Group A explored the effect of negative reinforcement on student behavior while Group B studied the effects of the reward system on student achievement. The AR outputs cited seemed to show that pre-service teachers' conceptual understanding enabled them to apply it in classroom practice.

\section{Table 1}

Classification of Pre-service Teachers Concept of Action Research

Characteristic of Description Sample Output

Action Research

Critical

Appreciative Inquiry

Participative

Soft Systems Methodology

Cyclic
Are used to challenge existing theories and practices to promote a better and correct understanding

Includes the combination of action and understanding; consists of several steps that include observation, planning, and action

Involves people that will take an active part in creating and implementing the plan

Is flexible for its rigor is based on the continuity on investigating an idea; each cycle is a chance to refine the theory

Integrates action and theory and explains the relationship of how the two affect each other

\author{
Negative reinforcement in the \\ classroom and student behavior- \\ Group A
The Effects of Modified Free-Inquiry Method on Students' Problem-Solving Skills in Grade 9 Physics - Group J

The use of cooperative learning in teaching Grade 8 Biology - Group I

\section{Psychosocial classroom climate and student achievement in science - Group D}

Addressing misconception on Earth Science through models - Group $G$

Another conceptual understanding of the respondents on action research is the nature of the study as a form of an appreciative inquiry. From the related literature, Dick (2015) described the appreciative inquiry as an active and reflective process that combines action and understanding. Some of the answers of respondents in the questionnaire seemed to agree that action research is a process of reflection of teachers in their teaching and making students reflect on their learning. Respondent 24 described "that through action research, problems in the classroom can be properly addressed by looking for appropriate solutions". Respondent 27 agrees that identifying classroom problems and planning for the solution is also a characteristic of action research.

Such conceptual understanding of some pre-service teachers seemed to lead them to appreciate the process of conducting action research and regard the ideas they discover valuable to their teaching endeavors. In their outputs, Group J conducted action research on how free inquiry activities can help their students improve their problem-solving skills. On the other hand, Group F investigated the effects of the degree of independence given to students on their ability to solve advanced physics problems. Both Groups $\mathrm{J}$ and $\mathrm{F}$ seemed to show in their outputs that AR-enabled them to reflect on their practices. As manifested in their outputs, pre-service teachers seemed to appreciate the role of AR in making them inquire further on their innovative practices.

Moreover, some respondents acknowledged that action research is participative. Respondent 17 said that "action research benefits both the teachers and students" while Respondent 8 said that "action research requires active action from teachers and students". On the other hand, Respondents 9 and 14 agree that action research can be a shared endeavor of a group of teachers or colleagues. Such conceptual understanding of pre-service teachers on a characteristic of action research seemed to lead Group I to investigate the effects of collaborative learning in teaching Grade 9 Biology. In the conduct of their research, they facilitated group 
activities and described how their students feel about the collaboration process, and determined if it affected their learning process. Moreover, members of Group I involved their critic teachers in the conduct of the study who served as observers while they facilitate the collaborative activities they prepared. With such observations, it seemed that indeed pre-service teachers realized that conducting AR is indeed participative.

Similar to the idea of Dick (2015) who described the process of action research to be cyclic in nature, there are also respondents who perceived that action research is a continuous process of planning, acting, and reflecting. The respondents who acknowledged the said nature described that action research is the utilization of scientific method in solving a certain problem. The focus of the said investigation is about classroom problems which planning for action and implementation follows. The process of observing, planning, and implementation continuously occurs to provide better understanding and solutions.

Particularly, Group $\mathrm{G}$ finds that their students have misconceptions about certain earth science concepts. Together, with their critic teacher, they planned on how to address the identified misconceptions. In effect, members of Group $\mathrm{G}$ decided to use models in their science activities and classroom discussion. They even use models and representations in their assessment procedures. After the implementation of their study, they identified if there was an improvement in student concept of their earth science lessons. In their study, they identified areas that can still be further studied. Therefore, with the output of the member of Group G, it can be inferred that as pre-service teachers their concept of AR as a cycle for improvement of practice seemed to help them with their classroom task.

Lastly, action research as a soft system methodology has been viewed by the respondents to share similarities with traditional research but employs less rigorous methods and has a more specific scope of the study. In a sample response, Respondent 22 said that "[a]ction research is somewhat similar to a traditional research but is focused more on classroom issues". The answer of Respondent 22 represents a portion of the responses that describes action research as a soft system of solving hard problems in the classroom.

The concept that AR as a soft system methodology may have guided the pre-service teachers of Group D who investigated the psychosocial effects of a classroom environment on students. What Group D meant with the term psychosocial environment is well-planned student interaction such as an ordered arrangement of chairs, use of meta cards for recitation, and even the pattern of student recitation. What prompted Group D to study the effects of a controlled and well-planned psychosocial environment is their difficulty on classroom management. With the output of Group D, they have shown that while classroom management is a hard problem for them, it can be solved through soft-system methodologies such as establishing rules and routines for their students. Moreover, the output of Group D shows that they have employed research strategies in a more contextualized setting through their AR.

\subsection{Pre-service Teachers Perception on the Importance Action Research}

Upon exposure to the different AR tasks, the present study investigates how pre-service teachers perceive action research and its importance in their professional training. Table 2 shows the result of the said investigations.

Primarily, as perceived by the respondents of the study, the purpose of action research is to identify common problems in the classroom and solve them using the methods of research. The results of the present seemed to agree with the ideas of Hobson, et.al. (2015) that the benefits of exposing pre-service teachers to action research involve the implementation of research-based procedures in addressing classroom situations. In other words, action research enables pre-service teachers to apply the theories that they have learned in the university in an actual classroom setting. Such benefit of action research has been acknowledged by $37 \%$ of the respondents. Respondent 12 said that "[a]ction research helps me to know what I shall do when I meet certain problems and to cope with the needs of the children." Simply put, pre-service teachers perceived that action research makes them solve classroom problems by applying theories that address the challenge encountered as Respondent 14 said 
Pre-service teachers on action research: Towards a training model for the task

"[a]ction research can help me as a teacher to gain new knowledge and see an actual application of theories learned from textbooks and school in a classroom situation." Therefore, by doing action research, pre-service teachers seemed to realize that the process can improve his or her teaching style.

Table 2

Perceived importance of action research

\begin{tabular}{lll}
\hline \multicolumn{1}{c}{ Perception } & \multicolumn{1}{c}{ Description } & Frequency \\
\hline $\begin{array}{l}\text { Application of theories into } \\
\text { action }\end{array}$ & $\begin{array}{l}\text { Solving classroom problems by applying the teaching } \\
\text { and learning theories in situations encountered in the } \\
\text { classroom }\end{array}$ & $37 \%$ \\
Reflection on teaching practices & Self-evaluation of strengths and weakness in teaching & $26 \%$ \\
$\begin{array}{l}\text { Preparation for in-service } \\
\text { teaching }\end{array}$ & Enhancement of teaching skills & $24 \%$ \\
Continuation professional growth & $\begin{array}{l}\text { Enhancement of research skills to prepare for } \\
\text { graduate studies }\end{array}$ & $13 \%$ \\
\hline
\end{tabular}

While most of the respondents perceived that action research allows them to apply theories into action, the other $24 \%$ sees action research to help them prepare in their teaching profession. Respondent 9 described that "action research helps teachers in the conduct of future school activities". Respondent 12 said that "action research will enable me to understand the teaching process". Most respondents who perceived action research to prepare them to become in-service teachers said that it will enhance their teaching strategies and improve their teaching skills. As researchers described in the related literature, pre-service teachers realized that action research helps them to possess teacher qualities to withstand classroom challenges (Ulla, et.al, 2017) and develop personal skills for effective teaching (Lattimer, 2012). With the perceptions of the pre-service teachers on the benefits of action research, it is comforting to note that they realize why they need to do the process.

"To realize my strengths and weaknesses" was an answer given by Respondent 4 for question number 2 . This type of response was classified under the 'reflection' category in the characteristic of action research (26\%). According to Rademaker (2013), action research makes teachers reflect on their practices and inform them of the changes they ought to make to improve the quality of their teaching. Similarly, Respondents 32 and 33 described that doing action research makes them self-reflect and self-evaluate their teaching practices. "The different processes of action research are primarily to understand students for teachers to plan and implement instruction effectively" according to Respondent 10. The congruence between the researchers' ideas and the respondents' on the reflective nature of action research is hoped that pre-service teachers will be able to use action research in their quest to refine their teaching practices.

Lastly, the pre-service teachers (13\%) also perceive that doing action research prepares them to be lifelong learners of the teaching profession. Specifically, teachers as lifelong learners involve pursuing further studies. Other Responses that were classified in this category described that pre-service teachers see action research as a procedure of learning more about what to teach, how to teach, and even how to give an appropriate assessment. When beginning teachers have mastered the processes of action research, it can help them succeed as they pursue graduate studies which would require the skills for research (Hobson et al., 2015). Respondent 8 said that “doing action research can help me improve my research skills when I will take my master's degree". While the researcher aims to expose pre-service teachers to action research for the enhancement of their teaching skills, the result of the process seemed to open the minds of the respondents to conduct the process not just for their classroom teaching but for personal improvement also. 
Montebon, D. R. T.

\subsection{Pre-service teachers' readiness for action research}

This section reports how ready are the pre-service teachers in doing action research. To describe the data better, the researcher grouped the criteria into two which are the basic research skills and supplemental research skills. With the basic research skills, the researcher meant to describe the skills of the pre-service teachers in conducting fundamental research procedures from identifying the problem to formulating a conclusion. On the other hand, the researcher also believes that in conducting research there are supplemental skills such as the ability to proceed with the task independently or collaboratively; these skills, he grouped as supplemental.

Table 3 shows the juxtaposed data of pre-service teachers' self-assessment report and the data from the assessment of their AR outputs. The juxtaposed area is based on the similarities of criteria involved in both pre-service teachers' self-assessment report and the data from the assessment of their AR outputs. Some measures that do not have equivalent in each form of assessment are reported as it is with blanks on its corresponding assessment area.

Table 3

Pre-service Teachers' Readiness in Conducting Action Research

\begin{tabular}{|c|c|c|c|c|c|}
\hline \multicolumn{2}{|r|}{ Area of Readiness } & \multicolumn{2}{|c|}{ Self-Assessment Report } & \multicolumn{2}{|c|}{$\begin{array}{c}\text { Assessment of } \\
\text { Research Output }\end{array}$} \\
\hline & & Mean & SD & Mean & SD \\
\hline \multirow{8}{*}{$\begin{array}{l}\text { Basic Research } \\
\text { Skills }\end{array}$} & Identifying a problem & 3.45 & 0.79 & 2.50 & 0.53 \\
\hline & $\begin{array}{l}\text { Finding and reviewing the } \\
\text { literature }\end{array}$ & 2.68 & 0.66 & 3.10 & 0.99 \\
\hline & Gathering data & 2.95 & 0.52 & & \\
\hline & $\begin{array}{l}\text { Analyzing and interpreting } \\
\text { data }\end{array}$ & 2.53 & 0.51 & 1.40 & 0.52 \\
\hline & Presenting the data & 2.55 & 0.60 & 1.60 & 0.84 \\
\hline & Arriving at a conclusion & 2.55 & 0.60 & 1.20 & 0.63 \\
\hline & Citing References & & & 1.20 & 0.63 \\
\hline & Observing Ethical Standards & & & 1.40 & 0.97 \\
\hline \multirow{5}{*}{$\begin{array}{l}\text { Supplemental } \\
\text { research skills }\end{array}$} & $\begin{array}{l}\text { Conducting research } \\
\text { independently }\end{array}$ & 2.16 & 0.59 & & \\
\hline & $\begin{array}{l}\text { Collaborating with colleagues } \\
\text { on doing research }\end{array}$ & 3.34 & 0.58 & & \\
\hline & $\begin{array}{l}\text { Presentation of Research } \\
\text { Reports }\end{array}$ & 2.87 & 0.74 & & \\
\hline & $\begin{array}{l}\text { Publishing research reports on } \\
\text { journals }\end{array}$ & 2.08 & 0.71 & & \\
\hline & $\begin{array}{l}\text { Over-all quality of the } \\
\text { Research Report }\end{array}$ & & & 1.20 & 0.63 \\
\hline \multicolumn{2}{|c|}{ Average of Readiness and Quality of Output } & 2.72 & 0.45 & 1.7 & 0.63 \\
\hline
\end{tabular}

Notes. ${ }^{*}$ Self-Assessment: 0.1 to $1.0=$ not ready; 1.1 to $2.0=$ slightly ready; $2.1-3.0=$ ready; $3.1-4.0=$ very much ready

**Assessment of Research Output: 0.1 to $1.0=$ does not meet standard; 1.1 to $2.0=$ nearly meet standard; $2.1-3.0=$ meet standard; 3.1-4.0=exceeds standard

Looking at the data in Table 3, it can be inferred that pre-service teachers' self-assessment report describes that they are 'ready' for the tasks of action research. However, the quality of their outputs as assessed is

28 Consortia Academia Publishing (A partner of Network of Professional Researchers and Educators) 
Pre-service teachers on action research: Towards a training model for the task

described to have 'nearly meet standard' only. The said results are further discussed in the succeeding paragraphs.

On basic research skills - The data in Table 3 shows that among the different basic research skills the criteria which had the highest mean is identifying the problem to be studied. Similarly, the assessment results for their output seemed to describe that most of the AR meet standards. Some positive descriptions include the ability of the pre-service teachers to distinguish real classroom problems and offer solutions through research. However, the assessment of the AR output suggests that pre-service teachers should be guided to write their research problems in a form that is appropriate, understandable, and clear to the reader. In other words, the pre-service teachers need to enhance how to present the objectives of their study in an explicit form where variables being studied are easily identified and how the relationships among them can be evaluated.

In terms of the related literature, the data on self-assessment and the assessment of their AR outputs seemed to agree with each other. The pre-service teachers reported that they are in general, 'ready' for the task while the $\mathrm{AR}$ assessment reveals that most of their outputs are exceeding standards. It has been observed by the researcher that most of the pre-service teachers have read and studied documents relevant to their problem and have written their ideas well on the related literature section of their paper. The researcher also observed that pre-service teachers have organized the sections well and have established how each section is relevant to their study. For some AR outputs, the concepts reviewed in the related literature were used to form the conceptual or the theoretical framework of the study. Minimal suggestions such as appropriate citation and paraphrasing are suggested.

On gathering data, it is also reported that pre-service teachers described that they are 'ready' for the task. Though there is no parallel section about gathering data in the rubric for assessing the AR outputs of the pre-service teachers, still the researcher tried to analyze the manuscripts. He observed that it appears that pre-service teachers were aware of the concept of research designs as revealed in their outputs that they were able to implement different research designs such as quasi-experimental with pre-test and post-test and qualitative studies using observation methods. While it is acknowledged by the researcher that pre-service teachers have a sound conceptual understanding of research designs, they still need to be more adept in deciding which strategy is more appropriate for their study. As an example, in the study of Group E on the effects of negative reinforcement they had an objective on finding out the perception of the students on their strategy. Instead of using a qualitative research design, they could have used a quantitative method using a questionnaire to better analyze the effects of their intervention. Therefore, the researcher suggests that pre-service teachers should be more exposed to different AR outputs that can serve as guides for their studies.

The pre-service teachers also indicated that they are 'ready' in doing the analysis, interpretation, and presentation of data. While the said claim of the pre-service teachers might be true in certain sense, the assessment of their outputs revealed that the quality of their AR outputs just 'nearly meet standards'. It means that the pre-service teachers need more enhancement on analyzing, presenting, and analyzing their data such as identifying more appropriate data analysis procedures, interpreting trends on their data, and writing a better summary of their findings. Specifically, the pre-service teachers need support on how to interpret quantitative data and qualitative data accurately. For the quantitative data, the pre-service teachers need to improve on how to infer from the quantities that they have presented on their outputs. Consequently, pre-service teachers need support on how to deal with qualitative data such as finding common themes and ideas in their studies.

In conclusion, the pre-service teachers' level of readiness can also still be enhanced. From their AR outputs, it has been observed that pre-service teachers need to work on how to make their conclusions responsive to their identified research questions. In other words, the coherence of the conclusion and the identified problem is a common challenge for pre-service teachers. Aside from coherence, it would also help pre-service teachers to formulate conclusions based on their gathered data only. As observed, it seemed that pre-service teachers need to have a better understanding of the different research terms such as conclusion, implications, and 
recommendations.

Another area being studied is the observation of ethical standards. The assessment of AR outputs shows that the pre-service teachers have 'nearly meet standards' for observing ethical standards. Among the ten different AR outputs analyzed, only two groups were able to state how they have observed ethical standards. Groups D and I explained to their student-respondents that the study they are conducting will not affect their grades and will only be used for improving their classroom instructional skill as teachers to be. On the other hand, most of the pre-service teachers need to be more aware of some ethical procedures such as treating controlled and experimental groups equally, describing the research locale anonymously, and obtaining consent from school authorities and parents.

Lastly, it has been observed that making appropriate references is a research skill that pre-service teachers need to work on. From their AR outputs, it has been observed that only a few of the manuscripts followed acceptable reference formats. However, the researcher also acknowledges that the format for citing references was not discussed well during the workshop and the practice teaching course orientation. Therefore, to improve this practice, it is suggested that the skill for citing and making references based on a certain standard be also given priority in training pre-service teachers for AR.

On supplemental research skills - In terms of supplemental research skills, the researcher deemed it important to study how ready is the pre-service for the task individually or collaboratively. Results in Table 3 show that pre-service teachers are more ready to do the task collaboratively rather than doing the task just on their own. Such readiness may have been influenced by their exposure to the research tasked which is always assigned by the group. Therefore, the researcher suggests that if possible, pre-service teachers should also be allowed to conduct AR individually.

In the area of research presentation, the pre-service teachers reported that they are 'ready' for the task. In the present study, no activity was initiated to allow pre-service teachers to report their work through oral research presentation. Thus, such claims of the pre-service teachers could not be verified or supported. Therefore, it is suggested that the institute design an activity in which pre-service teachers can be given the chance to present their work in a research presentation activity whether at an institutional, a national, or an international level.

Lastly, among the different research skills studied, basic and supplemental combined, it has been observed that pre-service teachers are least ready in the area of publishing their AR output. Such claim is seemed to be explained by the observation on the overall quality of the pre-service teachers' AR output to have only reached a nearly standard level in general. Furthermore, the assessment made for the overall quality of the AR outputs of the pre-service teachers is seemed to be supported with the different observations on the different research skills discussed in the previous paragraphs of this section. With the said observations, the researcher suggests that pre-service teachers should be given support in finalizing their AR outputs that they might be worthy of presentation and publication.

\section{Conclusions and recommendations}

Based on the responses on the questionnaire, it was found that pre-service teachers seemed to possess a conceptual understanding similar to what has been identified by other researchers that action research is a process that is active and reflective, participative, cyclic, qualitative, critical, and rigorous. The varied conceptual understanding of the pre-service teachers appears to have guided them in the conduct of their AR as shown in their outputs. Furthermore, the results on the questionnaire seemed to describe that pre-service teachers have different perceptions on the purpose of action research. Such perception includes the application of theories into action, reflection on teaching practices, response to classroom problems, preparation for in-service teaching, and support for continuing professional growth.

Lastly, results show that while pre-service teachers reported that they are 'ready' for almost all the different 
Pre-service teachers on action research: Towards a training model for the task

aspects of action research, the quality of their work still needs improvement to meet the standards set. Therefore, continuous support and improvement on preparing pre-service teachers for the task is still relevant.

Ultimately, the present research is to determine if the institutional practice of exposing pre-service teachers to action research helps them prepare for in-service challenges. Consequently, the results of the present research seemed to show that 'yes' it does. From the different conceptual understanding of the pre-service teachers and their perception of the AR tasks, it can be inferred that the process helped them to prepare for the different challenges for teaching and learning. However, the pre-service teachers' readiness for action research still needs enhancement. The researcher believes that the 'support' for pre-service teachers to succeed with their action research is through a program that is more responsive to their needs.

That said, the researcher reflected on the different processes of the Institute in preparing pre-service teachers for the AR tasks. From the insights he gathered from the study, the researcher proposes a model for preparing pre-service teachers for AR tasks. The said model is shown in Figure 2.

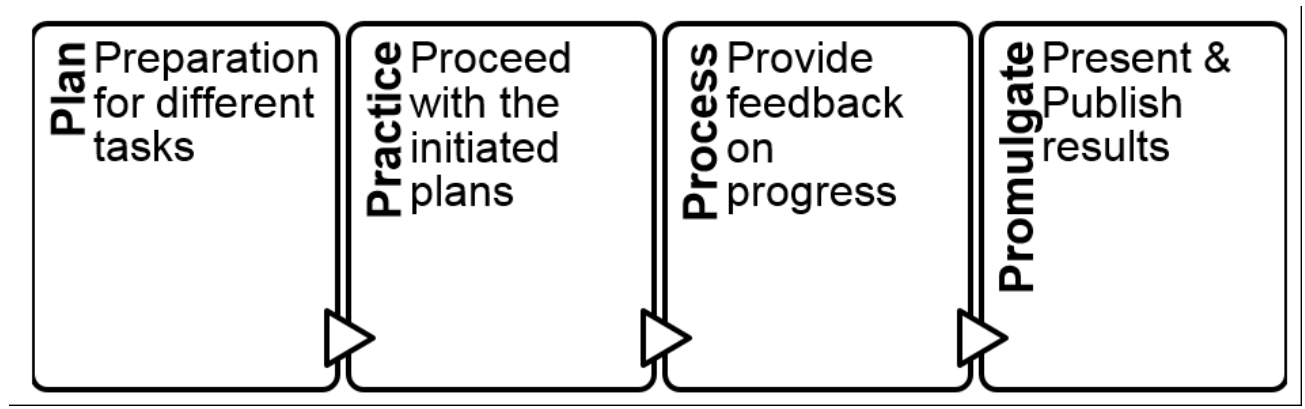

Figure 2. The 4-P's model for preparing pre-service teachers for action research

Prepare. Results of the study revealed that while pre-service teachers indicated 'readiness' to conduct action research in the classrooms, there are still areas that they need assistance. The assessment of these areas of readiness is essential to design a program that can better equip pre-service teachers for the action research tasks. In doing so, action research competencies should be identified and be prepared by a teacher education institution to identify specific learning outcomes for the course.

At the Institute where the study was conducted, pre-service teachers are given a lecture workshop on action research before their deployment in their field study and practice teaching sites. With the said activity, the pre-service teachers can reveal their misconception on action research and identify the challenges to perform the task. In effect, the process can guide the Institute to design further activities and programs to assist pre-service teachers with the task.

Practice. After the preparation stage, pre-service teachers should be provided with the opportunity to apply the knowledge and skills they have learned in the conduct of action research. In the conduct of the action research by pre-service teachers, the role of the supervisors as mentors is crucial. The mentoring activities may include assistance in identifying a feasible research problem, identifying feasible action research studies, ethical issues to be considered, and the preparation of the manuscript.

In proceeding with the conduct of action research, several stages are encouraged at the Institute. First, the classroom problem that will be solved in the action research and the methodologies to answer is presented to the practice teaching supervisors. If the problem and the methodologies are approved, the conduct of the actual research proceeds. In the said stage, the supervisors assist the pre-service teachers in terms of validating research instruments, setting meetings and dialogues with critic teachers, and observe the actual conduct of the research process. However, it should be clear that the supervisors' role is only to assist with the research. After the implementation stage, the pre-service teachers are then given time to interpret their results and present them to the supervisor. The result of the research is then communicated to the stakeholders concerned such as critic teachers and school principals. 
Process. After the conduct of the action research, supervisors need to process the experiences of the pre-service teachers. The processing of experiences is essential to determine further ways of assistance and the continuous improvement of the instructional program on action research.

With the experience of the researcher as a supervisor of the pre-service teachers, the processing happened during the debriefing procedure after the practice period. With the said procedures, the researcher was able to determine the challenges that were encountered by the pre-service teachers in the conduct of their action research.

Promulgate. As the outputs of the pre-service teachers have been submitted, the supervisors can choose manuscripts that have the potential to be presented or be published. Research presentations and publishing manuscripts in journals can provide pre-service teachers with the experiences that can further enhance their skills as teacher-researchers. Conversely, presenting in a conference and publishing the action research of the pre-service teachers can add to knowledge generation in the teaching and learning process and teacher preparation.

However, research presentation and publication of the AR outputs of the pre-service teachers are acknowledged by the researcher to be a challenge to the institutes' experience. To help address the concern in the said area, the researcher suggests several activities. For research presentations, the pre-service teachers should be encouraged to join different research conferences where they can showcase their AR outputs, or the institute can design a program for the said purpose. For publication, the researcher suggests establishing an institutional journal that will publish the action researches of the pre-service teachers.

\section{References}

Bisson, M. J., Gilmore, C., Inglis, M., \& Jones, I. (2016). Measuring conceptual understanding using comparative judgment. International Journal of Research in Undergraduate Mathematics Education, 2(2), 141-164. https://doi.org/10.1007/s40753-016-0024-3

Clayton, C., \& Meadows, G. (2013). Action research projects in pre-service teacher education. Teacher Educators Journal, 20, 5-18. https://doi.org/10.1016/j.tate.2020.103194

Dick, B. (2015). Reflections on the SAGE Encyclopedia of Action Research and what it says about action research and its methodologies. Action Research, 13(4), 431-444. https://doi.org/10.1177/1476750315573593

Hobson, L., Colvin, A., Butler, D., Boone, \& S., Booker-Thomas, C. (2015). Strategies for mentoring and engaging undergraduate students in planning, conducting, writing, and presenting research. Journal of Teacher Action Research, 2(1), 30-41.

Lattimer, H. (2012). Action research in pre-service teacher education: Is there value-added? Inquiry in Education, $3(1)$.

Manguerra, R. (2019). Implications of action research on basic education. Paper presented at a seminar-workshop on action research of the Philippine Normal University, Manila, Philippines.

Morales, M. P. E. (2016). Participatory action research (PAR) cum action research (AR) in teacher professional development: A Literature review. International Journal of Research in Education and Science, 2(1), 156-165.

Rademaker, L. (2013). Action research in education: A practical guide—a book review. Inquiry in Education, $4(2)$.

Ryan, T. G., Young, D. C., \& Kraglund-Gauthier, W. L. (2017). Action research within pre-service teacher education. Transformative Dialogues: Teaching \& Learning Journal, 10(3).

Soprano, K., \& Yang, L. (2013). Inquiring into my science teaching through action research: A case study on one pre-service teacher's inquiry-based science teaching and self-efficacy. International Journal of Science and Mathematics Education, 11, 1351-1368. https://doi.org/10.1007/s10763-012-9380-x

Ulla, M. B., Barrera, K. B., \& Acompanado, M. M. (2017). Philippine classroom teachers as researchers: 
Pre-service teachers on action research: Towards a training model for the task

Teachers' perceptions, motivations, and challenges. Australian Journal of Teacher Education, 42(11). https://doi.org/10.3316/informit.245575319218538

Ulvik, M. M., \& Riese, H. (2016) Action research in pre-service teacher education - a never-ending story promoting professional development. Professional Development in Education, 42(3), 441-457. https://doi.org/10.1080/19415257.2014.1003089

Zhogbhi, W. A. (2012). President's page: Plan, do, study, act: A proven path to progress. Journal of the American College of Cardiology, 60(1), 76-79. https://doi.org/10.1016/j.jacc.2012.05.006 
Montebon, D. R. T.

34 Consortia Academia Publishing (A partner of Network of Professional Researchers and Educators) 